RESEARCH PAPER

J. Food Sci. \& Technol. Nepal. Vol, 7 (22-30), 2012

ISSN: 1816-0727

\title{
Chemical Composition, Anti-neuraminidase, and Anti-atherogenic Activities of the Essential Oil from two Varieties of Alpinia zerumbet Leaves
}

\section{ATUL UPADHYAY ${ }^{1,2^{*}}$, JAMNIAN CHOMPOO $^{1}$, RIZWAN AHMAD $^{1,2}$, SHINKICHI TAWATA $^{1}$ and LUC PIETERS $^{2}$}

\author{
${ }^{1}$ Department of Bioscience and Biotechnology, Faculty of Agriculture, University of the Ryukyus, Senbaru 1, Nishihara-cho, \\ Okinawa 903-0129, Japan. \\ ${ }^{2}$ Natural Products \& Food-Research and Analysis, University of Antwerp, Universiteitsplein 1, 2610, Antwerp, Belgium.
}

The present study describes the chemical composition and neuraminidase (NA) enzyme inhibition and anti-atherogenic properties of the essential oils (EO) of two varieties of Alpinia zerumbet (alpinia) leaves. A total of forty eight compounds were identified using GC-MS studies, which showed that tairin variety contained more compounds than shima variety. The EO inhibited NA in a dosedependent manner with $I C_{50}$ values of $41.5 \pm 2.7$ and $62.3 \pm 3.1 \mu \mathrm{g} / \mathrm{ml}$ for tairin and shima varieties, respectively. Furthermore, the kinetic studies of NA inhibitions revealed that tairin EO exhibited slow, time-dependent and mixed type of inhibitions. It seems that the minor components of tairin EO have better inhibitory properties. In order to assess the anti-atherogenic activities of EO, inhibitions of 15-lipoxygenase (15-LOX) and low density lipoprotein (LDL) oxidation were investigated. The results also showed that tairin EO had better activities against 15-LOX and LDL oxidation (IC $C_{50}=235 \pm 7$, and $\left.133 \pm 3 \mu \mathrm{g} / \mathrm{ml}\right)$, than shima EO (IC $=465 \pm 12$, and $195 \pm 5 \mu \mathrm{g} / \mathrm{ml})$. Finally, the acute toxicity analysis using Caenorhabditis elegans showed that LC $C_{50}$ values were more than $2500 \mu \mathrm{g} / \mathrm{ml}$. These findings suggest that tairin EO could be a possible candidate for further investigations in search for bioactive compounds against neuraminidase.

Keywords: Alpinia zerumbet, Essential oil, Neuraminidase inhibition, Anti-atherogenic activity, Toxicity

\section{Introduction}

Alpinia [Alpinia zerumbet (family Zingiberaceae)] is a perennial ginger growing widely in the subtropics and tropics. It is used in folk medicine for its anti-inflammatory, bacteriostatic, and fungistatic properties (Zhoghbi et al., 1999). The aqueous extract of its leaves has demonstrated hypotensive activity (Laranja et al., 1991) mainly due to flavonoids and kava pyrones (Mpalantinos et al., 1998). In Okinawa, two varieties of alpinia are widely found: tairin and shima. Tairin [A. zerumbet (Pers.) B. L. Burtt \& R. M. Sm. var. excelsa Funak \& T. Y. Ito] is a taller plant with long stems whereas shima [A. zerumbet (Pers.) B. L. Burtt \& R. M. Sm.] is short and has bushy structures. Both kinds of leaves are used to prepare a traditional food, $m u$-chi, and it is believed that it prevents from catching cold.

In our previous studies with alpinia leaf, we have demonstrated antioxidant and antimicrobial activities (Elzaawely et al., $2007 \mathrm{a}-\mathrm{c})$. We have also reported the advanced glycation end product and HIV-1 integrase and neuraminidase (NA) inhibitions by alpinia leaf (Chompoo et al., 2011; Upadhyay et al., 2011a). Furthermore, we identified anti-atherogenic properties and skin diseased related enzyme inhibition activities of alpinia leaf(Chompoo et al., 2012a, b). Recently, we showed that alpinia leaf extract can increase the lifespan of Caenorhabditis elegans (Upadhyay et al., 2013). In this study, we investigated the anti-neuraminidase and anti-atherogenic properties of essential oil (EO) obtained from two varieties of alpinia leaf.

\footnotetext{
*Correspondence author E-mail: atul.ppadhyay@ua.ac.be
}

The pharmacological properties of alpinia EO have been reported by several researchers (Laranja et al., 1991; Bezerra et al., 2000; Leal-Cardoso et al., 2004). Besides, alpinia EO has been associated with the antimicrobial and larvicidal activities (Cavalcanti et al., 2004; Victoria et al., 2009). However, this is the first report on the NA inhibitions and anti-atherogenic activities of alpinia EO. We further investigated the kinetic mechanism of NA inhibition by the EO of tairin variety and also studied its acute toxicity using $C$. elegans.

\section{Materials and Methods}

Extraction of EO from alpinia leaf- The EO was obtained from $500 \mathrm{~g}$ of fresh alpinia leaf by steam distillation for $4 \mathrm{hr}$. The distillate was extracted with diethyl ether and the solvent was carefully removed under vacuum at $35^{\circ} \mathrm{C}$. The obtained EO was dissolved in methanol and kept under refrigeration until use.

Neuraminidase inhibition assay- The enzyme assay was performed as reported previously (Upadhyay et al., 2011a,b) by measuring the amount of 4-methylumbelliferone that is cleaved by the influenza virus NA (Sigma, M8639) from the flurogenic substrate, 4-methylumbellifery-1- $\alpha-{ }_{-}-\mathrm{N}$ acetylneuramic acid sodium salt hydrate (NANA) (Sigma, M8639). In all assays, samples were dissolved in methanol at appropriate concentrations, and methanol was used as control. Briefly, the reaction was started by addition of NANA to previously added enzyme and sample, and fluorescence was measured in spectrofluorometer (Corona Electric, Japan). The excitation wavelength was set at $360 \mathrm{~nm}$, and the emission wavelength was set at $450 \mathrm{~nm}$. For kinetic studies, we used a time-driven protocol with initial velocity recorded over 
a range of substrate concentrations for different inhibitor concentrations $(0,30,40,50$, and $60 \mu \mathrm{g} / \mathrm{ml})$. Secondary plot was drawn by plotting the slopes of the obtained lines $(\mathrm{Km} /$ $\mathrm{Vm}$ ) against the substrate concentrations. For time dependent studies, we obtained progress curves for $600 \mathrm{~s}$ at several preincubation times using $40 \mu \mathrm{g} / \mathrm{ml}$ of EO and the slopes of lines were plotted against pre-incubation time. To study the effect of enzyme concentrations on the inhibitory activity by EO, we used different concentrations of NA at EO concentration of $40 \mu \mathrm{g} / \mathrm{ml}$. The inhibition was calculated using the following equation.

$$
\% \text { Inhibition }=\left[1-\left(\mathrm{S}-\mathrm{S}_{0}\right) /\left(\mathrm{C}-\mathrm{C}_{0}\right)\right] \times 100
$$

Where, $\mathrm{S}$ and $\mathrm{C}$ represent relative fluorescence units (RFU) for sample and control after reaction time and $\mathrm{S}_{0}$ and $\mathrm{C}_{0}$ are RFU at zero time.

\section{Anti-atherogenic activities}

15-LOX inhibition assay-Enzyme inhibition was determined as described previously in borate buffer $(0.2 \mathrm{M}, \mathrm{pH} 9.0)$ by measuring the increase in absorbance at $234 \mathrm{~nm}$ in $5 \mathrm{~min}$ after addition of 15-LOX, using linoleic acid $(134 \mu \mathrm{M})$ as substrate (Lyckander and Malterud, 1996). The final enzyme concentration was 500 units $/ \mathrm{ml}$ and the test samples were dissolved in DMSO solutions. All the measurements were carried out at least twice using ferulic acid as positive control. Calculations of enzyme activity were carried out as previously described, and $\mathrm{IC}_{50}$ values were determined by linear interpolation between the measuring points closest to $50 \%$ activity.

LDL cholesterol oxidation assay- The oxidation of LDL was investigated as described by Rattan \& Arad, 1998. $\mathrm{CuSO}_{4}-$ induced oxidized-LDL generation were performed using 100 $\mu \mathrm{L}$ of $220 \mu \mathrm{g} / \mathrm{ml} \mathrm{LDL}$ incubated at $37^{\circ} \mathrm{C}$ in dark with $10 \mu \mathrm{L}$ of $55 \mu \mathrm{M} \mathrm{CuSO}_{4}$ and $10 \mu \mathrm{L}$ of EO for $24 \mathrm{~h}$. The reaction was stopped by adding $50 \mu \mathrm{L}$ of $1 \mathrm{M}$ EDTA and placing the sample at $-20{ }^{\circ} \mathrm{C}$ for TBA reactive substance (TBARS) assay. The generation of malonyldialdehye (MDA) equivalents during LDL oxidation was estimated by the TBARS assay using the method described elsewhere (Steinbrecher et al., 1994). LDL oxidation was carried out as described above. After oxidation, LDL was mixed with $1.5 \mathrm{ml}$ of $0.67 \%$ TBA and $1.5 \mathrm{ml}$ of $20 \%$ TCA. After placing samples in boiling water $\left(98^{\circ} \mathrm{C}\right)$ for $30 \mathrm{~min}$, the reaction product was kept for $30 \mathrm{~min}$ at $25^{\circ} \mathrm{C}$ and centrifuged for $15 \mathrm{~min}$ at $4^{\circ} \mathrm{C}$. The supernatants were read on a spectrophotometer at $532 \mathrm{~nm}$, using the blank containing $220 \mu \mathrm{g} / \mathrm{ml}$ LDL only. The yields of MDA were used as a standard and the results were expressed as nanomoles of MDA equivalents.

\section{GC-MS analysis}

The compounds of EO were identified using DB-5MS fused silica capillary column (30 m x $0.25 \mathrm{~mm}$ i.d., $0.25 \mu \mathrm{m}$; Agilent Technologies, J and W Scientific Products, Folsom, CA, USA). The carrier gas was helium and the GC oven temperature program was as follows: $80{ }^{\circ} \mathrm{C}$ hold for $1 \mathrm{~min}$, raised at $10{ }^{\circ} \mathrm{C} / \mathrm{min}$ to $220{ }^{\circ} \mathrm{C}$, followed by raised to $330{ }^{\circ} \mathrm{C}$ at $20{ }^{\circ} \mathrm{C} / \mathrm{min}$ and hold for $6 \mathrm{~min}$. The injector and detector temperatures were set at $250{ }^{\circ} \mathrm{C}$ and $280{ }^{\circ} \mathrm{C}$, respectively and the injection volume was $1.0 \mu \mathrm{L}$ in the splitless mode. Mass spectra were scanned form $m / z$ 50-600 amu and the electron impact ionization energy was $70 \mathrm{eV}$. Quantitative determinations of EO components were done based on the peak area measurements. Retention indices were determined relative to the retention times of a series of $n$-alkane standards (C7 to C31, Restek Corporation, PA, USA), and compared with published values [Elzaawely 2007a-c; Shellie et al., 2002; Sibanda et al., 2004).

\section{Acute toxicity assessment of EO using $C$. elegans}

The acute toxicity of tairin EO was investigated according to a procedure described previously with slight modifications (Ura et al., 2002). The assay used wild type N2 strains, obtained from Caenorhabditis Genetic Center, University of Minnesota, MN, USA. Synchronization of worm culture was achieved by treating gravid hermaphrodites with bleach $(50 \%$ sodium hypochlorite; $2.5 \mathrm{M}$ sodium hydroxide) and recovering the hatched L1 larvae on nematode growth medium (NGM) plates. Day four larva (L4) were collected from the NGM plates and washed several times using S-basal medium. About 30-40 larvae in $500 \mu \mathrm{l} \mathrm{S}$-basal were transferred to $1.5 \mathrm{ml}$ of eppendorf tubes and were exposed to various concentration of tairin EO at $20{ }^{\circ} \mathrm{C}$. After incubating for $24 \mathrm{~h}$, the S-basal medium containing both living and dead nematodes were transferred to fresh NGM plates and the numbers of nematodes living and dead were counted. Survival was scored as the number of animals responsive to the gentle touch by platinum tip under dissecting microscope. The median lethal concentration $\left(\mathrm{LC}_{50}\right)$ was calculated using the PROBIT method.

\section{Statistical analysis}

$\mathrm{IC}_{50}$ values were expressed as mean \pm standard error by plotting the curve with percentage of inhibition versus concentration of the individual experiments measured $(n=$ 3). Statistical analysis was performed by one-way ANOVA and upon significant difference, means were separated using Tukey's HSD range test at $P=0.01$. All statistical analyses were performed using SPSS version 16.0 for Windows.

\section{Results and Discussion}

Chemical composition of the $\boldsymbol{E O}$ - The GC-MS analyses identified 39 major compounds in tairin variety while only 14 compounds could be identified in Shima variety. The EO was a complex mixture mainly consisting of monoterpenes and sesquiterpenes. The chemical structures of major compounds identified in EO of two varieties of alpinia leaf are shown in Figure 1A. 


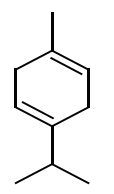

i)

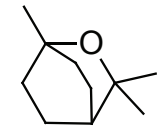

ii)

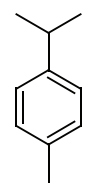

iii)

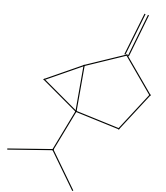

iv)<smiles>CC1=CCC(O)(C(C)C)CC1</smiles>

v)

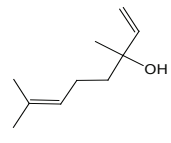

vi)

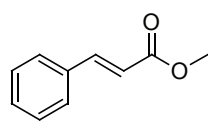

vii)

(A)

(B)



Figure 1. (A) Chemical structures of major compounds present in the EO of tairin and shima leaf i) $\gamma$-terpinene, ii) cineole, iii) $p$-cymene, iv) sabinene, v) 4-cravamenthenol, vi) $\beta$-linalool, and vii) methyl cinnamate. (B). Concentration dependent inhibition of NA activity by EO of tairin and shima varieties.

The major compounds in the EO were $\gamma$-terpinene (14.59\%), cineole (13.82\%), $p$-cymene (13.50\%), sabinene (12.51\%), and p-cravamenthenol (11.92\%) for tairin variety. Other compounds with significant presence were terpinolene (4.19\%), ?-thugene $(4.12 \%)$, caryophyllene oxide (3.02\%), caryophyllene $(2.4 \%), \alpha$-pinene $(2.02 \%)$, and $\alpha$-terpineol $(1.28 \%)$. In the case of shima variety, cineole $(37.8 \%$ ) was the major compound followed by $\beta$-linalool $(17.12 \%)$. The other major compounds identified were methyl cinnamate $(6.34 \%)$, benzylacetone $(4.21 \%)$, and $\alpha$-terpineol $(3.36 \%)$.

The amount and number of compounds varied greatly in two different varieties with only five compounds identified in both varieties. The identified compounds with their retention index and amount in percentage for two different varieties are listed in Table 1. All the compounds are arranged in the order of their retention times.

Table 1. The main chemical components of the essential oil from two varieties of alpinia leaf

\begin{tabular}{|c|c|c|c|c|}
\hline & \multirow{2}{*}{ Compounds } & \multirow{2}{*}{$\begin{array}{c}\text { Retention } \\
\text { Index }\end{array}$} & \multicolumn{2}{|c|}{ Peak area $(\%)$} \\
\hline & & & Tairin & Shima \\
\hline 1 & $\alpha$-Thugene & 929 & 4.12 & - \\
\hline 2 & $\alpha$-Pinene & 934 & 2.02 & - \\
\hline 3 & Norborndadiene & 943 & 0.08 & - \\
\hline 4 & Camphene & 947 & 0.22 & - \\
\hline 5 & Benzaldehyde & 963 & - & 1.59 \\
\hline 6 & Sabinene & 974 & 12.51 & - \\
\hline 7 & $\beta$-Pinene & 976 & 3.15 & - \\
\hline 8 & Myrcene & 989 & 0.69 & - \\
\hline 9 & $\alpha$-Phellandrene & 1002 & 0.31 & - \\
\hline 10 & Terpinolene & 1014 & 4.19 & - \\
\hline 11 & $p$-Cymene & 1024 & 13.50 & - \\
\hline 12 & 1,8-Cineole & 1031 & 13.82 & 37.80 \\
\hline 13 & $\gamma$-Terpinene & 1059 & 14.59 & - \\
\hline
\end{tabular}




\begin{tabular}{|c|c|c|c|c|}
\hline 14 & cis- $\beta$-Terpineol & 1068 & 0.55 & - \\
\hline 15 & $\beta$-Linalool & 1100 & 0.50 & 17.12 \\
\hline 16 & 2,5-Norbornadiene & 1111 & - & 0.71 \\
\hline 17 & cis- $p$-Menth-2-en-1-ol & 1121 & 0.59 & - \\
\hline 18 & Terpinen-4-ol & 1173 & 11.92 & - \\
\hline 19 & $\alpha$-Terpineol & 1193 & 1.28 & 3.36 \\
\hline 20 & trans-p-Menth-1-en-3-ol & 1206 & 0.42 & - \\
\hline 21 & Benzylacetone & 1237 & 0.06 & 4.21 \\
\hline 22 & Piperitone & 1248 & 0.03 & 0.1 \\
\hline 23 & Bornyl acetate & 1280 & 0.37 & - \\
\hline 24 & Cumic alcohol & 1287 & 0.18 & - \\
\hline 25 & Carvacrol & 1296 & 0.13 & - \\
\hline 26 & 2-tert-Butylphenyl pivalate & 1299 & - & 1.23 \\
\hline 27 & Ethyl-3-hydroxy-3-methylbutanote & 1302 & - & 0.09 \\
\hline 28 & Isopiperitenon & 1306 & - & 0.18 \\
\hline 29 & Thymol & 1317 & 0.05 & - \\
\hline 30 & 2-Hydroxy-3,5-dimethylcyclopent-2-en-1-one & 1319 & - & 0.13 \\
\hline 31 & $p$-Menth-1,4-dien-7-ol & 1324 & 0.07 & - \\
\hline 32 & Methyl cinnamate & 1381 & - & 6.34 \\
\hline 33 & Caryophyllene & 1411 & 2.40 & - \\
\hline 34 & 2,6-Diethylnitrosobenzene & 1426 & - & 0.69 \\
\hline 35 & $\alpha$-trans-Bergamoene & 1428 & 0.09 & - \\
\hline 36 & Aristole-9-ene & 1434 & 0.15 & - \\
\hline 37 & $\alpha$-Humulene & 1446 & 0.38 & - \\
\hline 38 & Butylcyclopentane & 1477 & - & 0.63 \\
\hline 39 & $\alpha$-Selinene & 1479 & 0.15 & - \\
\hline 40 & $\gamma$-Cadinene & 1505 & 0.42 & - \\
\hline 41 & $\alpha$-Bulnesene & 1514 & 0.25 & - \\
\hline 42 & Nerolidol & 1559 & 0.38 & - \\
\hline 43 & Caryophyllene oxide & 1573 & 3.02 & - \\
\hline 44 & Carotol & 1593 & 0.13 & - \\
\hline 45 & Humulene epoxide & 1599 & 0.29 & - \\
\hline 46 & $\beta$-Eudesmol & 1646 & 0.65 & - \\
\hline 47 & iso-Aromdendrene epoxide & 1662 & 0.21 & - \\
\hline \multirow[t]{2}{*}{48} & $\alpha$-Zingiberene & 1701 & 0.02 & - \\
\hline & Total & - & 93.89 & 74.18 \\
\hline
\end{tabular}


Neuraminidase inhibitory activities of EO- With the everpresent threat of a pandemic derived from influenza virus and the emergence of resistant strain to synthetic drugs, the importance of searching for novel compounds from plantbased source intensifies. In this regard, we investigated the NA inhibitory activities of EO of two varieties of alpinia leaves. The results showed a dose-dependent inhibition of NA with a sharp increase at the lower concentrations (Figure 1B). The $\mathrm{IC}_{50}$ value of NA inhibition by tairin was found to be 41.5 $\pm 2.7 \mu \mathrm{g} / \mathrm{ml}$, while that of shima variety was $62.3 \pm 3.1 \mu \mathrm{g} /$ $\mathrm{ml}$ (Table 2). Our previous study reported that alpinia leaves and rhizomes inhibited NA with $\mathrm{IC}_{50}$ of 43 and $57 \mu \mathrm{g} / \mathrm{ml}$, respectively. In this study, the activity of tairin was similar to the leaves while it had better results than the rhizomal extracts, however shima $\mathrm{EO}$ showed a lesser activity than our previous study (Upadhyay et al., 2011a).

Table 2. $\mathbf{I C}_{50}$ (in $\left.\mu \mathrm{g} / \mathrm{mL}\right)$ values of different inhibitory activities of EO.

\begin{tabular}{|c|c|c|}
\hline Sample & Tairin & Shima \\
\hline Neuraminidase & $41.5 \pm 2.7$ & $62.3 \pm 3.1$ \\
\hline 15-LOX & $235 \pm 7$ & $465 \pm 12$ \\
\hline LDL oxidation & $133 \pm 3$ & $195 \pm 5$ \\
\hline
\end{tabular}
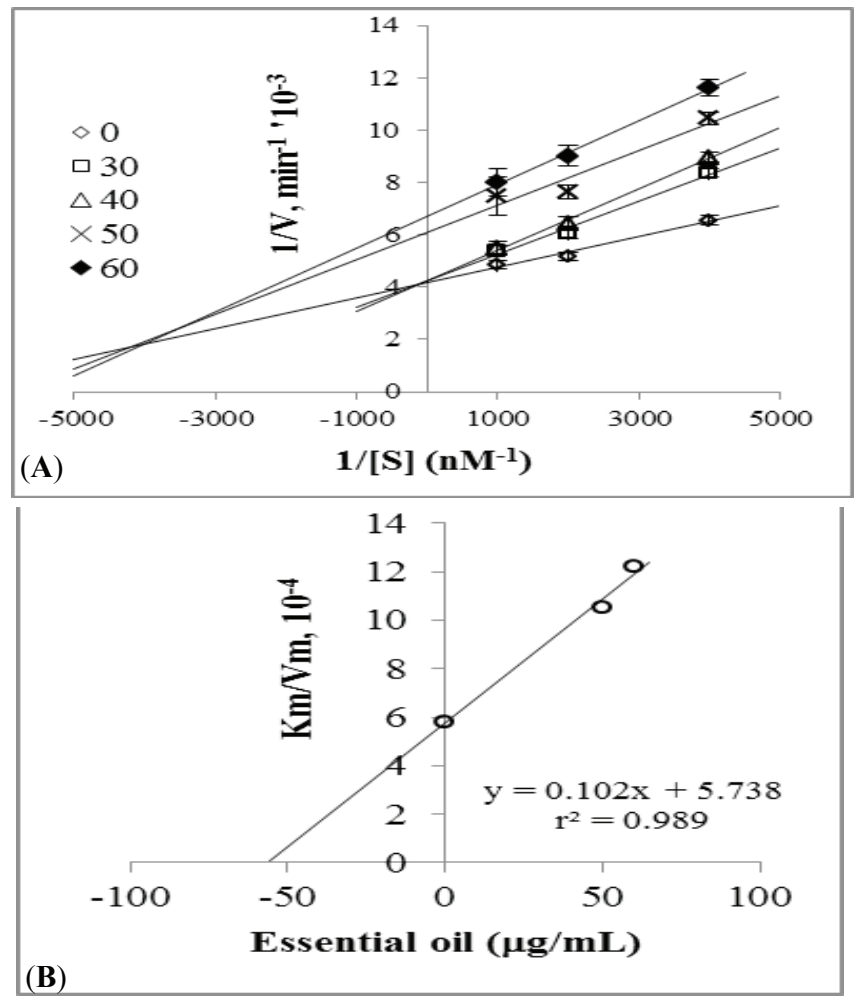

Figure 2. Effect of tairin EO on neuraminidase inhibition. (A) Lineweaver-Burk plot in the presence of $\mathrm{EO}$ at concentrations of $0,30,40,50$, and $60 \mu \mathrm{g} / \mathrm{ml}$. (B) Secondary plot of LineweaverBurk plot. The slopes were plotted against the respective concentrations.
We conducted kinetic studies of enzyme inhibition using tairin $\mathrm{EO}$ (Figure 2A). At EO concentrations less than its $\mathrm{IC}_{50}$ values (30 and $40 \mu \mathrm{g} / \mathrm{ml}$ ), the enzyme was competitively inhibited with $\mathrm{Km}$ value of $0.04 \mathrm{~min}^{-1}$, while at higher concentrations (50 and $60 \mu \mathrm{g} / \mathrm{ml}$ ), EO had a mixed type of inhibition against NA. This suggests that at lower concentrations, EO binds with the free enzyme or the enzyme-substrate complex at its active site, however, at higher concentrations; it binds to a site different from the active site where the substrate binds. The estimated $\mathrm{K}_{i}$ value of $56.25 \mu \mathrm{g} / \mathrm{ml}$ was obtained from the secondary plot of Lineweaver-Burk plot (Figure 2B).

We further investigated the inhibitory mechanism of tairin $\mathrm{EO}$ at its $\mathrm{IC}_{50}$ concentration. We began with exploring the effect of pre-incubation time on the inhibition of the hydrolysis of neuramic acid. The results did not indicate any specific relationship between the pre-incubation time and enzyme activity (Figure 3A). Furthermore, when the slopes of the lines were plotted against the time, it was found that there is a decrease in the slope till a pre-incubation time of 20 min, making it a slow, time-dependent inhibitor (dotted line, Figure 3B).

However, when the time of pre-incubation was increased, it was found that there is a linear rise in the slope indicating that the residual activity increased with pre-incubation time (dashed lines, Figure 3B). These results suggest that for a short pre-incubation time, it follows kinetics of a slow inhibitor, while at prolonged incubation; the EO behaves in a different manner. The reasons for this behavior are yet to be understood, however, we assume that it may be due to the presence of a mixture of components in EO. On carrying out the statistical analysis, it was found that the inhibitory activities at preincubation times of 10 and $20 \mathrm{~min}$ are significantly higher than that of the control, thereby indicating the optimal preincubation times.

Furthermore, when the effect of enzyme concentration on NA activity was probed, it was found that with increasing enzyme concentration, the residual activity of the enzyme also increased (Figure 4), which is a natural phenomenon with most of the enzyme inhibitions, and agrees with our previous results (Upadhyay et al., 2011 a,b). 

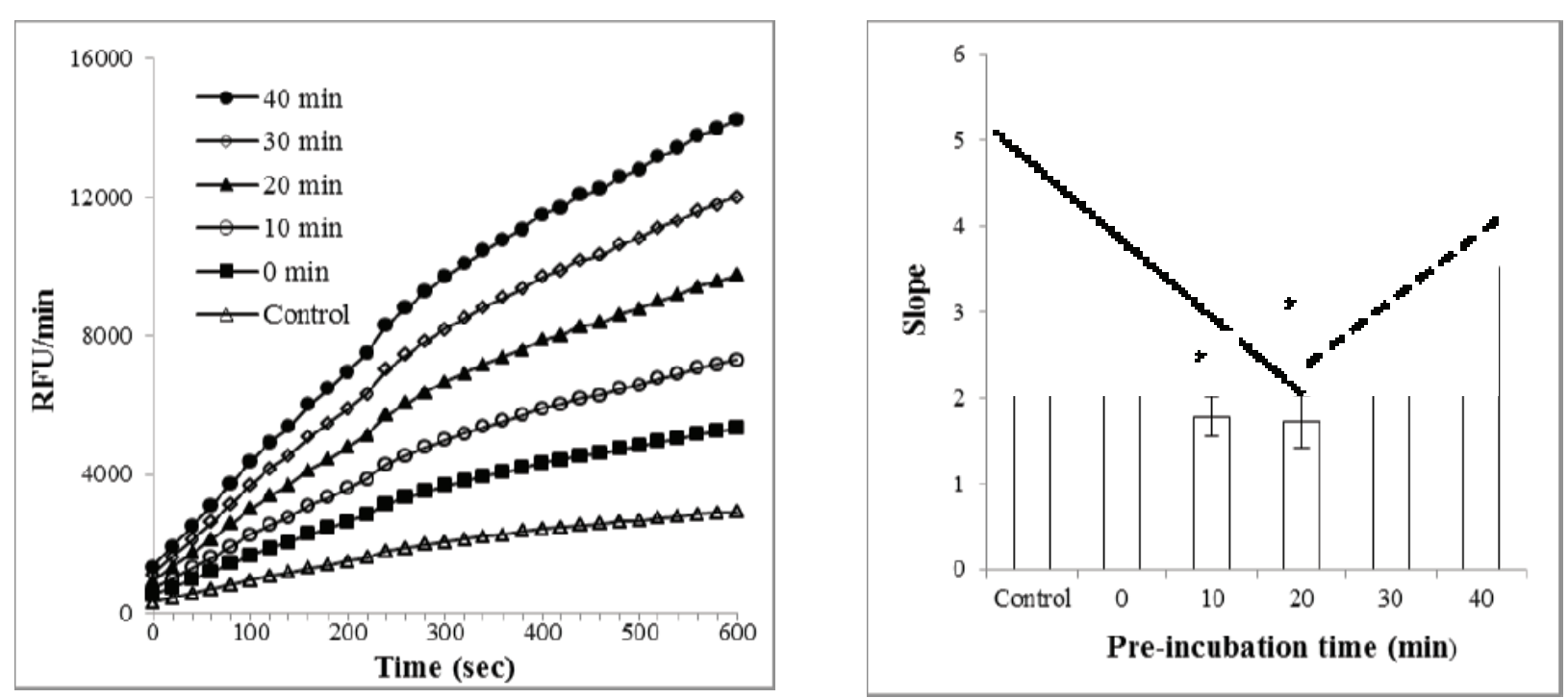

Figure 3. Effect of pre-incubation time on hydrolysis of substrate by NA: (A) time-dependent inhibition of NA in the presence of $40 \mu \mathrm{g} / \mathrm{ml}$ tairin EO; (B) slopes of the lines of panel $A$ at different incubation time



Figure 4. Effect of enzyme concentration on NA inhibition. A typical plot of residual activity of $\mathrm{NA}$ at various enzyme concentrations $(0-0.2 \mathrm{U} / \mathrm{ml})$ in the presence of $\mathrm{mg} / \mathrm{ml}$ tairin $\mathrm{EO}$

NA inhibitions by major compounds identified in tairin EOIn order to identify the EO components with NA inhibitory activity, we investigated the NA inhibitions by four major compounds of tairin EO. It was found that $p$-cymene, ?-terpinine, and terpinen-4-ol had higher inhibitory activity against NA with $\mathrm{IC}_{50}$ of $140 \pm 7,280 \pm 9$, and $400 \pm 12 \mu \mathrm{g} /$ $\mathrm{ml}$, respectively (Figure 5). However, 1,8-cineole a major compound in both the varieties had poor inhibition properties $\left(\mathrm{IC}_{50}>3000 \mu \mathrm{g} / \mathrm{ml}\right)$. Since the tairin EO had better inhibitory properties than the individual compounds, it seems that the minor components in the EO may have greater roles in the inhibition of NA.

There are reports on inhibitory activities of EO of botanical families against the influenza virus (Zai-Chang et al., 2005; Hayashi et al., 2007). In one study, compounds like terpinen4-ol, terpinolene and $\alpha$-terpineol have shown the inhibitory effect of influenza $\mathrm{A} / \mathrm{PR} / 8$ virus at doses below the cytotoxic dose (Garozzo et al., 2009). However, in a recent report, it was found that although tea tree oil has anti-influenza virus activity, it did not have anti-NA activity (Garozzo et al., 2011).
Although the effectiveness of alpinia EO against the influenza virus is yet to be confirmed, our results are quite promising since we found NA inhibitions at low micro molar range and may have better activities against the virus.

Anti-atherogenic activities of $\mathbf{E O}$ - It is widely accepted that the oxidative modification of plasma lipoproteins, particularly LDL, plays an important role in the initiation of atherosclerosis. The process of atherosclerosis begins with the accumulation of lipids within the artery wall (Shepherd et al., 1995). 15-LOX is a lipid-oxidizing enzyme that is considered to contribute to the formation of oxidized lipids in the atherosclerotic lesions (Bocan et al., 1998). Furthermore, when the levels of plasma triglycerides are low, high density lipoprotein (HDL) cholesterol levels tend to be high. HDL opposes atherosclerosis directly, by removing cholesterol from foam cells by inhibiting the oxidation of LDL (Barter, 2005). Beside LDL, the 15-LOX form hydroperoxy derivatives of linoleic acid and arachidonic acid and is induced in atherosclerotic plaques (Harats et al., 2000). Hence, if LDL cholesterol oxidation and/or 15-LOX are inhibited, the formation of atherosclerosis may be prevented.

Our results showed that EO of tairin had significantly better activities than shima EO. In both EOs, there was linear inhibition of LDL cholesterol oxidation (Figure 6A) while 15LOX was inhibited logarithmically (Figure 6B). In both cases, increase in inhibitory activity was seen in a dose-dependent manner. The $\mathrm{IC}_{50}$ values for the 15-LOX and LDL oxidation inhibitions for tairin EO were found to be $235 \pm 7 \mu \mathrm{g} / \mathrm{ml}$ and $133 \pm 3 \mu \mathrm{g} / \mathrm{ml}$, respectively, while for shima EO the values were $465 \pm 12 \mu \mathrm{g} / \mathrm{ml}$ and $195 \pm 5 \mu \mathrm{g} / \mathrm{ml}$, respectively (Table 2). These results were also similar to NA inhibitions results where tairin EO was found superior to shima EO. 


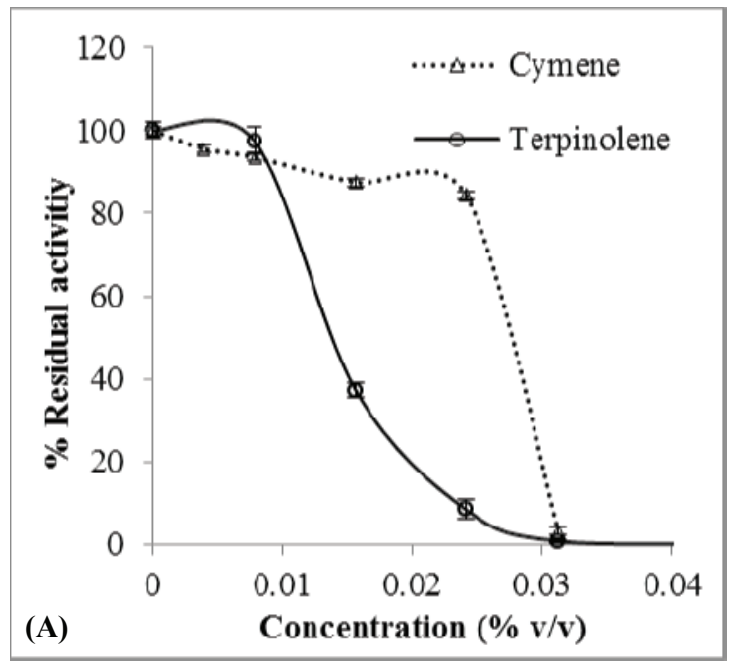

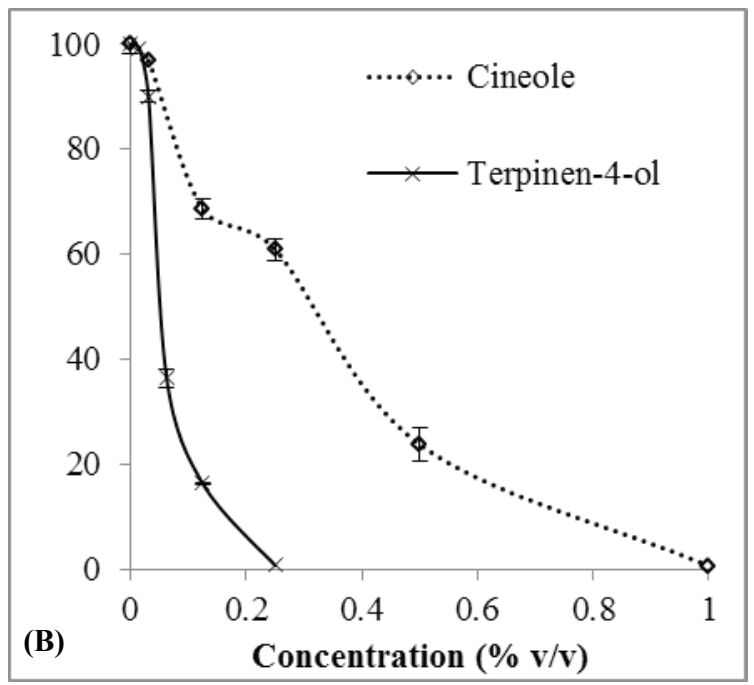

Figure 5. Concentration-dependent NA inhibitions by the major compounds identified in tairin EO

A number of reports on the inhibitory activities of terpenoids against 15-LOX (Amagata et al., 2003) and LDL oxidation (Laranjinha et al., 1995; Dugas et al., 1998) are available. Our study also identified several terpenoidal compounds in EO of alpinia and we assume that these compounds might have a role in inhibiting the formation of atherosclerosis by mediating inhibitions of 15-LOX and LDL oxidation. However, the differences in the activities between the two varieties seem to be due to a large variation in the number and amount of the compounds present in the EO of two different varieties.

Acute toxicity analysis of tairin EO using C. elegans- The determination of median lethal concentration $\left(\mathrm{LC}_{50}\right)$ is recognized as first step for risk assessment of synthetic and natural chemicals. Therefore, in order to consider tairin EO as possible candidate for drug designing, toxicity evaluation was very essential. In this regard, we measured the acute toxicity of tairin EO using C. elegans as animal model. Two independent trials were performed with three replications in each trial. It was found that increasing concentration of EO had significant effect on the survival of C. elegans, however, almost $50 \%$ survival was seen at a concentration of $2500 \mu \mathrm{g} /$ $\mathrm{mL}$ (Figure 7). The $24 \mathrm{~h}-\mathrm{LC}_{50}$ values of 2730 and $2885 \mu \mathrm{g} / \mathrm{ml}$ in two different assays were obtained from PROBIT analysis. These results show that the toxicity of tairin EO is very low when compared with the concentrations used in inhibiting NA.
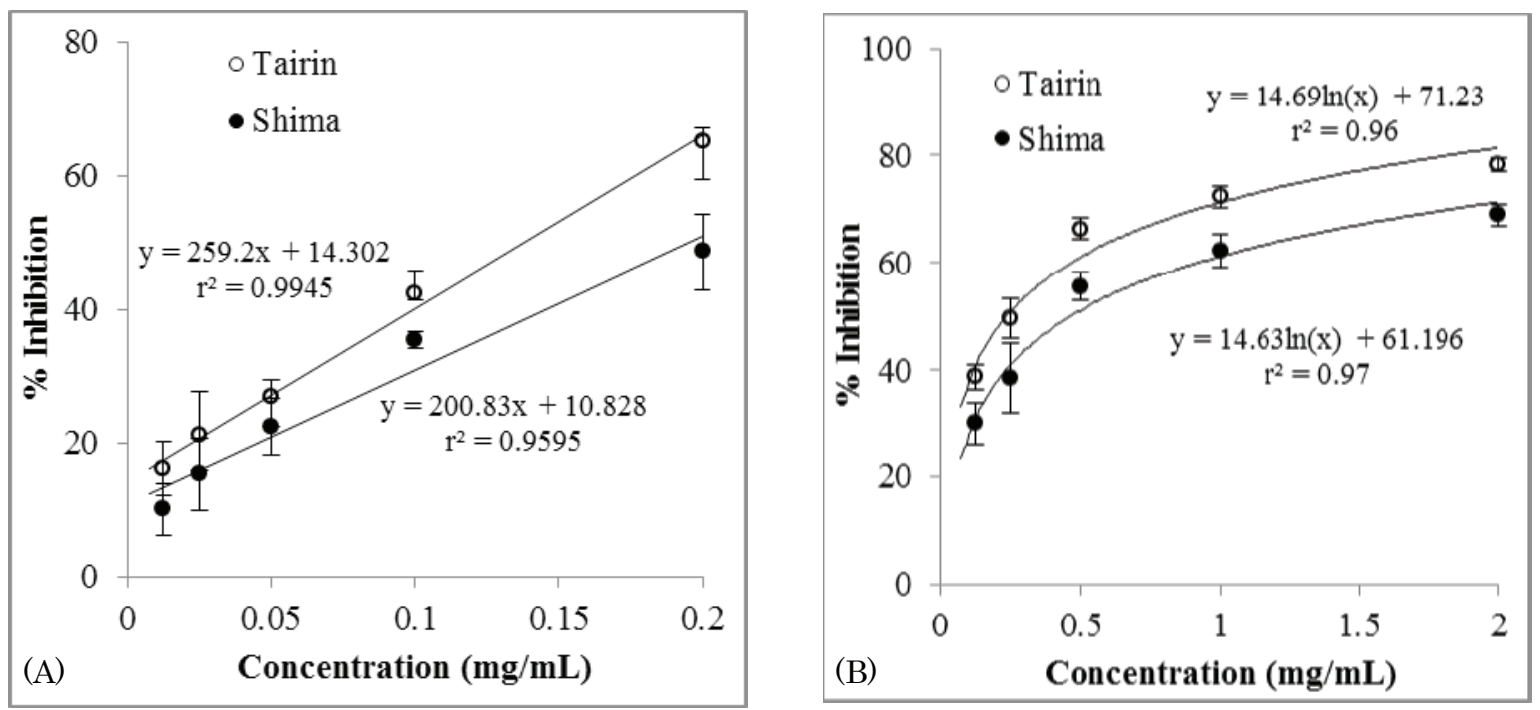

Figure 6. Concentration-dependent inhibition of LDL (A) and 15-LOX (B) enzymes by EO of tairin and shima varieties. 




Figure 7. Concentration-response survival rate of $C$. elegans after $24 \mathrm{~h}$ exposure to tairin EO. Values represent mean $\pm \mathrm{SE}$ for six different results

\section{Conclusion}

Essential oils have always been a subject of great interests in anti-oxidant and antimicrobial activities. However, in this study we identified novel properties of alpinia leaf EO against NA and atherogenic activities. Our results indicate that EO of alpinia leaf could be used as sources in inhibiting these diseases. The low $\mathrm{IC}_{50}$ value for neuraminidase inhibitions by alpinia EO will encourage the researchers to further investigate viral inhibition at cellular level and/or in vivo studies.

\section{References}

Amagata T., Whitman S., Johnson T.A., Stessman C.C., Loo C.P. and Lobkovsky E. et al. (2003). Exploring spongederived terpenoids for their potency and selectivity against 12-human, 15-human, and 15-soybean lipoxygenases. Journal of Natural Products, 66:230-235.

Barter P (2005). The role of HDL-cholesterol in preventing atherosclerotic disease. European Heart Journal Supplement, $7 F$ :F4-F8.

Bezerra M. A., Leal-Cardoso J. H., Coelho-de-Souza A. N., Criddle D. N. and Fonteles, M. C. (2000). Myorelaxant and antispasmodic effects of the essential oil of Alpinia speciosa on rat ileum. Phytotherapy Research, 14:549551.

Bocan T. M., Rosebury W.S., Mueller S. B., Kuchera S., Welch K. and Daugherty, A. et al., (1998). A specific 15-lipoxygenase inhibitor limits the progression and monocytemacrophage enrichment of hypercholesterolemia-induced atherosclerosis in the rabbit. Atherosclerosis, 136:203-216.

Cavalcanti E. S. B., de Morais S.M., Lima M. A. A. and Santana E. W. P. (2004). Larvicidal activity of essential oils from Brazilian plants against Aedes aegypti L. Memorias do Instituto Oswaldo Cruz, 99:541-544.
Chompoo J., Upadhyay A., Fukuta M. and Tawata S. (2012). Effect of Alpinia zerumbet components on antioxidant and skin diseases-related enzymes. BMC Complementary and Alternative Medicine, 12:106-114.

Chompoo J., Upadhyay A., Gima S., Fukuta M. and Tawata S. (2012). Antiatherogenic properties of acetone extract of Alpinia zerumbet seeds. Molecules, 17:6237-6248.

Chompoo J., Upadhyay A., Kishimoto W., Makise T. and Tawata S. (2011). Advanced glycation end products inhibitors from Alpinia zerumbet rhizomes. Food Chemistry, 129:709-715.

Dugas T. R., Morel D.W. and Harrison E. H. (1998). Impact of LDL carotenoid and a-tocopherol content on LDL oxidation by endothelial cells in nature. Journal of Lipid Research, 39:999-1007.

Elzaawely A. A., Xuan T. and Tawata S. (2007a). Changes in essential oil, kava pyrones and total phenolics of Alpinia zerumbet (Pers.) B. L. Burtt. and R.M. Sm leaves exposed to copper sulphate. Environmental and Experimental Botany, 59:347-353.

Elzaawely A. A., Xuan T. and Tawata S. (2007b). Essential oils, kava pyrones and phenolic compounds from leaves of Alpinia zerumbet (Pers.) B. L. Burtt. and R.M. Sm. and their antioxidant activity. Food Chemistry, 103:486-494.

Elzaawely A. A., Xuan T., Koyama, H. and Tawata S. (2007c). Antioxidant activity and contents of essential oil and phenolic compounds in flowers and seeds of Alpinia zerumbet (Pers.) B.L. Burtt. and R. M. Sm. Food Chemistry, 104:1648-1653.

Garozzo A., Timpanaro R., Bisignano B., Furneri P.M., Bisignano G. and Castro A. (2009). In vitro antiviral activity of Melaleuca alternifolia essential oil. Letters in Applied Microbiology, 49:806-808.

Garozzo A., Timpanaro R., Stivala A., Bisignano G. and Castro, A. (2011). Activity of Melaleuca alternifolia (tea tree) oil on influenza virus A/PR/8: study on the mechanism of action. Antiviral Research, 89:83-88.

Harats D., Shaish A., George J., Mulkins M., Kurihara H. and Levkovitz, H. et al. (2000). Overexpression of 15-lipoxygenase in vascular endothelium accelerates early atherosclerosis in LDL receptor-deficient mice. Arteriosclerosis, Thrombosis, and Vascular Biology, 20:2100-2105.

Hayashi K., Imanishi N., Kashiwayama Y., Kawano A., Terasawa K. and Shimada, Y. et al. (2007). Inhibitory effect of cinnamaldehyde, derived from Cinnamomi cortex, on the growth of influenza A/PR/8 virus in vitro and in vivo. Antiviral Research, 74:1-8.

Laranja S.M., Bergamaschi C.M. and Schor N. (1991). Evaluation of acute administration of natural products with potential diuretic effects, in humans. Memorias do Instituto Oswaldo Cruz, 86:237-240. 
Laranjinha J., Vieira O., Madeira V. and Almedia L. (1995). Two related phenolic oxidants with opposite effects on vitamin E content in low density lipoproteins oxidized by ferrylmyoglobin: consumption vs regeneration. Archives of Biochemistry and Biophysics, 2:373-381.

Leal-Cardoso J. H., Moreira M. R., da Cruz G. M. P., de Morais S. M., Lahlou M. S. and de-Souza, A. N. C. (2004). Effects of essential oil of Alpinia zerumbet on the compound action potential of the rat sciatic nerve. Phytomedicine, 11:549-553.

Lyckander I. M. and Malterud K. E. (1996). Lipophilic flavonoids from Orthosiphon spicatus prevent oxidative inactivation of 15-lipoxygenase. Prostaglandins, Leukotrienes \& Essential Fatty Acids, 54:239-246.

Mpalantinos M. A., de Moura R. S., Parente J. P. and Kuster R. M. (1998). Biologically active flavonoids and kava pyrones from the aqueous extract of Alpinia zerumbet. Phytotherapy Research, 12:442-444.

Rattan A. K. and Arad Y. (1998). Inhibition of LDL oxidation by new estradiol receptor modulator compound LY-139478, comparative effect with other steroids. Atherosclerosis, 136:305-314.

Shellie R., Mondello L., Marriott P. and Dugo G. (2002). Characterisation of lavender essential oils by using gas chromatography-mass spectrometry with correlation of linear retention indices and comparison with comprehensive two-dimensional gas chromatography. Journal of Chromatography A, 970:225-234.

Shepherd J., Cobbe S. M., Ford I., Isles C. G., Lorimer A. R. and Macfarlane P. W. et al., (1995). Prevention of coronary heart disease with pravastatin in men with hypercholesterolemia. New England Journal of Medicine, 333:1301-1307.

Sibanda S., Chigwada G., Poole M., Gwebu E.T., Noletto J.A. and Schmidt, J.M. et al., (2004). Composition and bioactivity of the leaf essential oil of Heteropyxis dehniae from Zimbabwe. Journal of Ethnopharmacology, 92:160-165.
Steinbrecher U. P., Parthasarathy S., Leake D. S., Witztum J. L. and Steinberg, D. (1994). Modification of low density lipoprotein by endothelial cells involves lipid peroxidation and degradation of low density lipoprotein phospholipids. Proceedings of National Academy of Sciences of the United States of America, 81:3883-3887.

Upadhyay A., Chompoo J., Taira N., Fukuta M. and Tawata S. (2013). Significant longevity extending effects of Alpinia zerumbet leaf extract on the lifespan of Caenorhabditis elegans. Bioscience Biotechnology and Biochemistry. (In Press).

Upadhyay A., Chompoo J., Kishimoto W., Makise T. and Tawata S. (2011a). HIV-1 integrase and neuraminidase inhibitors from Alpinia zerumbet. Journal of Agricultural and Food Chemistry, 59:2587-2862.

Upadhyay A., Chompoo J., Taira N., Fukuta M., Gima S. and Tawata S. (2011b). Solid-phase synthesis of mimosine tetrapeptides and their inhibitory activities on neuraminidase and tyrosinase. Journal of Agricultural and Food Chemistry, 59:12858-12863.

Ura K., Kai T., Sakata S., Iguchi T. and Arizono, K. (2002). Aquatic acute toxicity testing using the nematode Caenorhabditis elegans. Journal of Health Sciences, 48:583-586.

Victorio C.P., Alviano D.S., Alviano C.S. and Lage C.L.S. (2009). Chemical composition of the fractions of leaf oil of Alpinia zerumbet (Pers.) B. L. Burtt and R. M. Sm. and antimicrobial activity. Brazillian Journal of Pharmacognosy, 19:697-701.

Zai-Chang Y., Bo-Chu W., Xiao-Sheng Y. and Qiang W. (2005). Chemical composition of the volatile oil from Cynanchum stauntonii and its activities of anti-influeza virus. Colloids Surface B, 43:198-202.

Zoghbi M. G. B., Andrade E. H. A. and Maia J. G. S. (1999). Volatile constituents from leaves and flowers of Alpinia speciosa K. Schum. and A. purpurata (Viell.) Schum. Flavour and Fragrance Journal, 14:411-414. 